\title{
Hydrothermally Synthesized CuO Powders for Photocatalytic Inactivation of Bacteria
}

\author{
R. AZIMIRAD ${ }^{a}, \mathrm{~S} \cdot \mathrm{SAFA}^{a}$ AND O. AKHAVAN ${ }^{b, *}$ \\ ${ }^{a}$ Malek-Ashtar University of Technology, Tehran, Iran \\ ${ }^{b}$ Department of Physics, Sharif University of Technology, P.O. Box 11155-9161, Tehran, Iran
}

(Received April 29, 2015)

\begin{abstract}
Various morphologies of monoclinic $\mathrm{CuO}$ powders were synthesized by hydrothermal treatment of copper nitrate, copper acetate or copper sulfate. The synthesized samples were characterized by scanning electron microscopy, X-ray diffractometry, the Fourier transform infrared spectroscopy, and diffuse reflectance spectrophotometry. Antibacterial activity of the samples was studied against Escherichia coli bacteria in dark and under visible light irradiation. Although the different precursors yielded the same band gap energies $(\approx 1.6 \mathrm{eV})$ for the synthesized $\mathrm{CuO}$ samples, they resulted in various morphologies (hierarchy of stabilized micro/nanostructures), specific surface areas, concentrations of $\mathrm{OH}$-surface groups, and visible light photocatalytic performances. The CuO nanorods synthesized from nitrate hydrothermal bath not only exhibited a considerable effective surface area, but also showed the highest concentration of absorbed OH-groups and subsequently, the strongest (photo)catalytic antibacterial properties $(\approx 37$ and $94 \%$ inactivation of the bacteria in dark and under visible light irradiation, respectively).
\end{abstract}

DOI: $10.12693 /$ APhysPolA.127.1727

PACS: $82.50 . \mathrm{Hp}, 82.50 .-\mathrm{m}$

\section{Introduction}

Copper oxide, as a $p$-type narrow band-gap semiconductor material, with capability to form various nanostructured morphologies (such as nanowalls [1], nanowires [2], nanoparticles [3], honeycombs [4], and hierarchical nanostructures $[5,6])$ has attracted great deal of attentions for versatile applications such as solar cells [7], electrochromic devices [8, 9], catalysis [10] and photocatalysis [11, 12], gas sensors [13], biosensors [14, 15], field-emitters [16, 17], and antibacterial materials [18-22]. In bactericidal applications, it has been confirmed that in contrast to low sensitivity of body tissue and skin to copper ions (as an advantage), microorganisms are extremely susceptible to copper ions and radicals photogenerated by $\mathrm{CuO}$ nanostructures [23]. Although, many investigations have been reported about antibacterial and even antiviral properties of various photoactive metal oxides such as $\mathrm{TiO}_{2}$ [24-27], $\mathrm{ZnO}[28,29]$ and $\mathrm{WO}_{3}[30], \mathrm{CuO}$ is an inexpensive material which can be also photocatalytically activated under visible light irradiation $[31,32]$.

Photocatalytic antibacterial activity of crystallized copper oxide particles with various shapes was studied by Pang et al. [33]. They found that all the morphologies of the crystalline particles were antibacterial materials. Meantime, by changing morphology from cubic to octahedral, the bactericidal property altered from general bacteriostasis to the high selectivity. Therefore, one can conclude that the well-defined $\mathrm{CuO}$ nanostructures with optimized size and morphology may show an improved state for the antibacterial application. Recently, it was

${ }^{*}$ corresponding author; e-mail: oakhavan@sharif .edu demonstrated that bactericidal effectiveness of metal oxide nanostructures significantly depends on the possibility of the direct interaction of the nanostructures with bacterial membrane, rather than the effects of released ions and radicals [34]. Therefore, more investigations about the influence of shape, size and surface functional groups of the nanostructures (here, $\mathrm{CuO}$ nanostructures) on their antibacterial performances are required.

In this work, antibacterial property of $\mathrm{CuO}$ powders (with various morphologies and surface chemical characteristics) was studied against Escherichia coli (E. coli) bacteria in dark and under visible light irradiation. To obtain $\mathrm{CuO}$ powders with various nanostructure morphologies, three precursors of copper nitrate, acetate, and sulfate were separately used in a hydrothermal process. Physico-chemical characteristics of the synthesized materials were studied by using X-ray diffractometry (XRD), Fourier transform infrared (FTIR) spectroscopy, and diffuse reflectance spectrophotometry (DRS).

\section{Experimental procedure}

\subsection{Materials and methods}

All the reagents with the analytical grade were purchased from Merck and used as received. Copper nitrate $\left(\mathrm{Cu}\left(\mathrm{NO}_{3}\right)_{3} \cdot 3 \mathrm{H}_{2} \mathrm{O}\right)$, copper acetate $\left(\mathrm{Cu}(\mathrm{Ac})_{2} \cdot \mathrm{H}_{2} \mathrm{O}\right)$ and copper sulfate $\left(\left(\mathrm{CuSO}_{4}\right) \cdot 5 \mathrm{H}_{2} \mathrm{O}\right)$ were applied as precursors of copper oxide. The urea $\left(\mathrm{CO}\left(\mathrm{NH}_{2}\right)_{2}\right)$ and cetyltrimethylammonium bromide (CTAB, $\mathrm{C}_{19} \mathrm{H}_{42} \mathrm{BrN}$ ) were employed as a hydrolysis agent and a cationic surfactant, respectively. The preparation process of $\mathrm{CuO}$ nanostructures was based on a hydrothermal synthetic procedure. The three types of super-saturated $\mathrm{Cu}^{2+}$ solutions were prepared by dissolving $0.26 \mathrm{M}$ of each copper salt in $30 \mathrm{ml}$ distilled water. Then, $12 \mathrm{mmol}$ of urea and $5.4 \mathrm{mmol}$ of CTAB were added to each one of the 
prepared solutions while the mixtures were stirred for 15 min to obtain blue homogeneous solutions. Subsequently, the mixtures were transferred into a teflon-lined stainless steel autoclave with $50 \mathrm{ml}$ capacity and main-

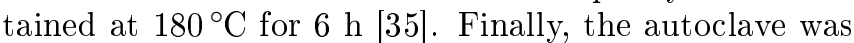
allowed to cool down to room temperature. The resulting black precipitate was collected and washed with ethanol and distilled water several times and dried under vacuum at $80^{\circ} \mathrm{C}$ for $5 \mathrm{~h}$. The copper oxides synthesized by using copper nitrate, copper acetate and copper sulfate were denoted as $\mathrm{CuO}$-[nitrate], $\mathrm{CuO}$-[acetate] and $\mathrm{CuO}$ [sulfate], respectively. It should be noted that we only applied the general recipes given in the literatures to obtain various morphologies of $\mathrm{CuO}$ powders using different precursors.

\subsection{Material characterization}

The morphology of the nanostructures was studied by a scanning electron microscope (SEM, Tescan Vega II). For the SEM imaging, powder samples were dispersed on a Si wafer and coated by a thin layer of gold using desktop sputtering, Nanostructured Coating Co., Iran. The crystalline structure of the prepared $\mathrm{CuO}$ samples were analyzed by using an XRD machine (JEOL diffractometer) equipped by a monochromatized $\mathrm{Cu} K_{\alpha}$ radiation source $(\lambda=1.54056 \AA)$ in the range of $15-65^{\circ}$ with step size of $0.1^{\circ}$. FTIR spectra were recorded by a Shimadzu$8400 \mathrm{~S}$ spectrometer in the range of $400-4000 \mathrm{~cm}^{-1}$ using $\mathrm{KBr}$ pellets. The optical characteristics of the samples were evaluated using a DRS (Shimadzu UV-1700) in the ultraviolet (UV) and visible ranges (wavelengths of 320$900 \mathrm{~nm}$ ). The effective surface area of the synthesized powders was evaluated through physical adsorption of methylen-blue (MB) molecules onto the surface of samples [36]. For measuring the MB adsorption, $5 \mathrm{mg}$ of each powder were added to $50 \mathrm{~mL}$ of $\mathrm{MB}$ dye $(20 \mu \mathrm{g} / \mathrm{mL})$, sonicated for $20 \mathrm{~min}$ and then left in dark for 1 day to obtain an equilibrium state. Afterwards, the relative decolorization of each solution as compared to the control sample (without any powder) was measured using the spectrophotometer at wavelength of $660 \mathrm{~nm}$.

\subsection{Antibacterial tests}

The antibacterial activity of the samples was studied against the E. coli, ATCC 25922 bacteria. Before the microbiological tests, all glassware and samples were sterilized at $120^{\circ} \mathrm{C}$ for $15 \mathrm{~min}$. The microorganisms were cultured on a nutrient agar plate at $37^{\circ} \mathrm{C}$ for $24 \mathrm{~h}$. The cultured bacteria were added into $10 \mathrm{ml}$ saline solution to reach the bacterial concentration to $\approx 108$ colony forming units per milliliter $(\mathrm{CFU} / \mathrm{ml})$. A fraction of the bacterial saline solution was diluted to obtain the concentration of $106 \mathrm{CFU} / \mathrm{ml}$. For the antibacterial test, $1 \mathrm{mg}$ of each powder sample was added into $1 \mathrm{ml}$ of the bacterial solution in a sterilized Petri dish. Then the samples were exposed to irradiation of a $110 \mathrm{~mW} / \mathrm{cm}^{2}$ mercury lamp at room temperature for $3 \mathrm{~h}$. Any irradiation below $410 \mathrm{~nm}$ was removed by using a cutoff filter (L41, Kenko Co.).
Then $100 \mu$ l of each bacterial suspension was spread on a nutrient agar plate and incubated at $37^{\circ} \mathrm{C}$ for $24 \mathrm{~h}$ in dark for counting the surviving bacterial colonies using an optical microscope. The reported data were the average value of three separate tests. The average dispersion of each data point was $\approx 15 \%$.

\section{Results and discussion}

SEM images of the $\mathrm{CuO}$ powders prepared with the different precursors are presented in Fig. 1. The copper nitrate hydrothermal bath resulted in formation of $\mathrm{CuO}$ nanorods with an average diameter and length of $\approx 100 \mathrm{~nm}$ and $\approx 2 \mu \mathrm{m}$, respectively (see Fig. 1a and b). Vayssieres [37] suggested that nitrate anions facilitate the growth rate of most densely packed and thermodynamically favorable planes toward a preferential orientation which in consistent with observed preferential crystallization of $\mathrm{CuO}$ in nitrate bath. Figure $1 \mathrm{c}$ and $\mathrm{d}$ shows that the copper acetate bath resulted in formation of microparticles constituted by nanoplatelet structures with thicknesses of $<100 \mathrm{~nm}$ and lateral dimensions of $\approx 1 \mu \mathrm{m}$, respectively. It has been suggested that negatively charged acetate anions adsorbed over the positively charged surface of $\mathrm{CuO}$ planes and prevented the growth of $\mathrm{CuO}$ in any preferential orientations out of the planes resulting in the formation of the platelet structure [38]. Figure 1e shows a flower-like morphology with a scaled feature which was stabilized in sulfate bath. The thickness and lateral dimension of the flakes was $<100 \mathrm{~nm}$ and $\approx 1 \mu \mathrm{m}$, respectively. The SEM images shown in Fig. 1e and f suggest that sulfate anions may cause the spontaneous growth of planes in more than one direction and so leads to formation of nanoflakes which are bonded to each other to form a flower-like micro/nanostructure [39].

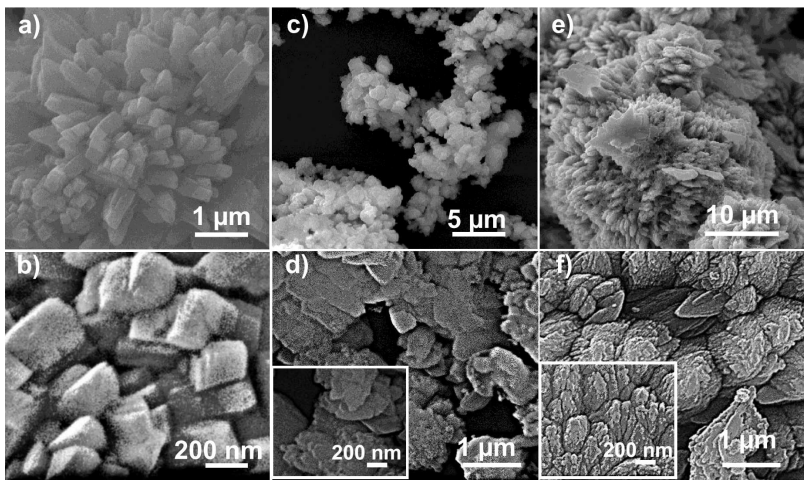

Fig. 1. SEM images of (a) and (b) CuO-[nitrate], (c) and (d) CuO-[acetate] and (e) and (f) $\mathrm{CuO}-$ [sulfate] micro/nano-structures at various magnifications. The scale bar of the insets of (d) and (f) is $200 \mathrm{~nm}$.

The effective surface area of the synthesized powders was evaluated through monitoring $\mathrm{MB}$ adsorption in dark resulting in partial decolorizations of the MB solution. It was found that the MB solution was decolorized to 
$\approx 88,93$, and $97 \%$ of the control sample for $\mathrm{CuO}$-[nitrate], $\mathrm{CuO}$-[acetate] and $\mathrm{CuO}-[$ sulfate], respectively. The adsorption area of each sample can be calculated assuming that each adsorbed MB molecule cover an area of $\approx 1.6 \mathrm{~nm}^{2}$ on surface of samples [40]. Therefore, the effective surface areas of the $\mathrm{CuO}$-[nitrate], $\mathrm{CuO}$-[acetate] and $\mathrm{CuO}-\left[\right.$ sulfate] were found to be $76.2,44.5$ and $19.1 \mathrm{~m}^{2} / \mathrm{g}$, respectively. The higher surface area of the $\mathrm{CuO}$-[nitrate] is consistent with its morphology shown in Fig. 1.

XRD patterns of the copper oxide micro/nanostructures are shown in Fig. 2. All of the observed peaks can be ascribed to $\mathrm{CuO}$ crystalline structure, based on the JCPDS card No. 05-0661. The two characteristic peaks at $2 \theta=35.6$ and $38.8^{\circ}$ are well indexed as (-111) $-(002)$ and (111) $-(200)$ planes of the monoclinic $\mathrm{CuO}$ crystalline structure. It is noteworthy that no other phases or impurities were crystallized in the synthesis procedures. Furthermore, the observed peaks in the $\mathrm{CuO}$-[nitrate] and $\mathrm{CuO}$-[acetate] samples are slightly higher and narrower, indicating a better crystallization and higher crystallite size of the $\mathrm{CuO}$ micro/nanostructures. The average crystallite size of the samples was determined by using the broadening of characteristic peaks in the Scherrer equation. Concerning this, the average crystallite size was found to be 25 , 25 and $20 \mathrm{~nm}$ for the $\mathrm{CuO}$-[nitrate], $\mathrm{CuO}$-[acetate] and $\mathrm{CuO}-[$ sulfate], respectively.

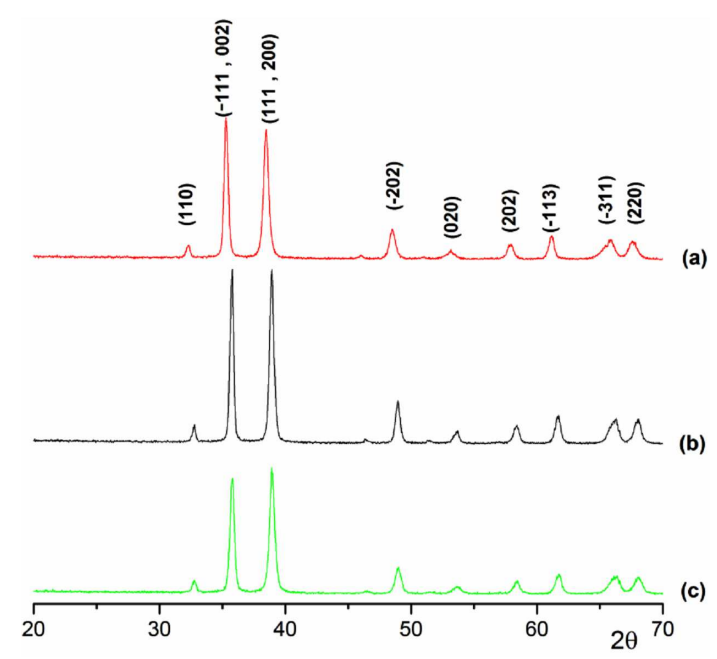

Fig. 2. XRD patterns of (a) CuO-[nitrate], (b) $\mathrm{CuO}$ [acetate] and (c) $\mathrm{CuO}$-[sulfate] micro/nanostructures.

The FTIR spectra of the $\mathrm{CuO}$ powders are shown in Fig. 3. The spectra were analyzed by correlating the observed absorption peaks to the known characteristic peaks of $\mathrm{CuO}$. The main absorption peaks located around 436,521 and $585 \mathrm{~cm}^{-1}$ are due to the formation of pure $\mathrm{CuO}$ monoclinic phase. The lack of any other peaks indicated that other impurities and unwanted phases were not formed. The peaks appeared at 3447 and $1645 \mathrm{~cm}^{-1}$ are assigned to the stretching and bending vibrations of the absorbed molecules of water and sur- face hydroxyl groups, respectively [12]. The blue shift of lower wave number peak can be assigned to size-induced lattice variations and existence of crystal defects [41] which is in close agreement with the results obtained by XRD analysis. It is also observed that the intensity of physically and/or chemically bonded $\mathrm{H}_{2} \mathrm{O}$-molecule and $\mathrm{OH}$-group bands over the surface is altered from considerable amounts for the $\mathrm{CuO}$-[nitrate] and $\mathrm{CuO}$-[acetate] samples to a negligible one for the $\mathrm{CuO}$-[sulfate] sample. This means that the $\mathrm{CuO}$-[nitrate] and $\mathrm{CuO}$-[acetate] powders contained more surface water and $\mathrm{OH}$ contents which are also necessary in more efficient photocatalytic reactions.

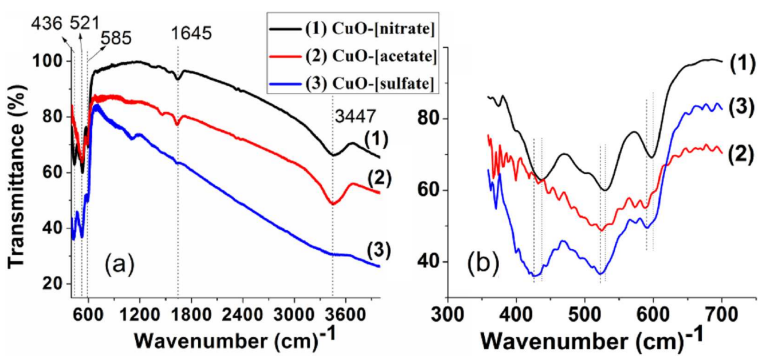

Fig. 3. (a) FTIR spectra of $\mathrm{CuO}$ micro/nanopowders synthesized by the various precursors and b) the lower wavenumber zone of the spectra to better distinguish the peak position.

The DRS of the $\mathrm{CuO}$ samples are shown in Fig. 4a. For $\mathrm{CuO}$ with the direct allowed transition, the absorption coefficient can be expressed by Tauc's relation $(\alpha h v)^{n}=A\left(h v-E_{\mathrm{g}}\right)$ where $\alpha$ is the absorption coefficient, $E_{\mathrm{g}}$ is the optical band gap, $A$ is a constant related to the effective mass, $h v$ is the photon energy and $n$ is the power depending upon the type of optical transition between valence and conduction bands $(n=2$ for direct and $1 / 2$ for indirect transitions). The magnitude of $E_{\mathrm{g}}$ is determined through plotting the graph of $(\alpha h v)^{2}$ versus $h v$. This graph should be linear at the absorption edge. We found that the best fitting at the absorption edge can be obtained for $n=2$, confirming the direct transition for $\mathrm{CuO}$. The value of $E_{\mathrm{g}}$ is obtained from the interception of the fitted line with the $h v$ axis. By this method, the values of $E_{\mathrm{g}}$ was found to be 1.67, 1.61, and $1.64 \mathrm{eV}$ for the $\mathrm{CuO}$-[nitrate], $\mathrm{CuO}$-[acetate] and $\mathrm{CuO}$-[sulfate], respectively. These values are in agreement with the values reported for $\mathrm{CuO}$ band gap energy [9]. It is known that chemical composition is main parameter affecting band gap value [42]. So, the nearly similar optical band gap of the samples can be attributed to formation of pure monoclinic $\mathrm{CuO}$ phase in all of the synthesized samples (see Fig. 2).

The antibacterial activity of the $\mathrm{CuO}$ powders was investigated against $E$. coli bacteria in dark and under visible light irradiation, as shown in Fig. 5. It is seen that among the samples, the $\mathrm{CuO}$-[nitrate] sample showed the highest antibacterial activity $(\approx 37 \%$ inactivation after $3 \mathrm{~h}$ ) in dark. This can be attributed to further di- 

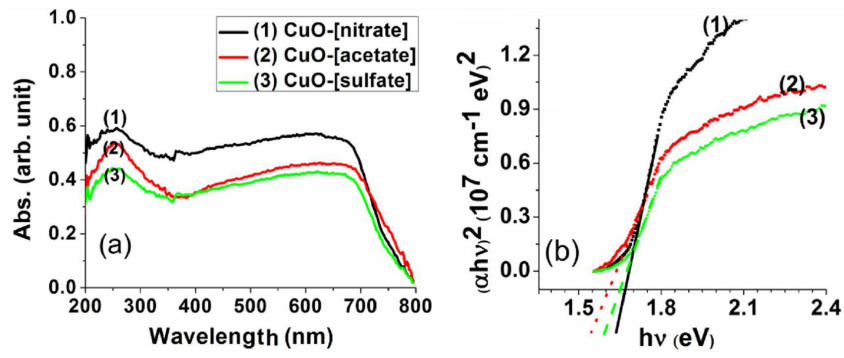

Fig. 4. (a) Optical absorption spectra and (b) corresponding Tauc plot of $\mathrm{CuO}$ micro/nano-powders synthesized by the various precursors.

rect contact between the bacteria and the sharp tips of the vertically aligned $\mathrm{CuO}$ nanorods located on the micro particles (see Fig. 1a) resulting in physical damages of the cell wall membrane of the bacteria, as reported previously for other sharp materials $[43,44]$. In addition, the high surface effective area of the $\mathrm{CuO}$-[nitrate] powder can be resulted in further release of $\mathrm{Cu}^{2+}$ ions as strong antibacterial agents [45].

The visible light photo-induced bactericidal activity of the $\mathrm{CuO}$ powders was also investigated, as shown in Fig. 5. Although the CuO-[sulfate] powder could inactivate a considerable fraction of the bacteria $(\approx 63 \%)$, the $\mathrm{CuO}$-[nitrate] and $\mathrm{CuO}$-[acetate] powders exhibited strong antibacterial activity under visible light irradiation for $3 \mathrm{~h}$ (especially the CuO-[nitrate] powder with $\approx 94 \%$ photoinactivation). The better photo-induced antibacterial activity of these samples (than the $\mathrm{CuO}$ [sulfate] sample) can be attributed to their further surface water and $\mathrm{OH}$ contents which can effectively involve in the free $\mathrm{OH}$ radical generation based photocatalytic processes.

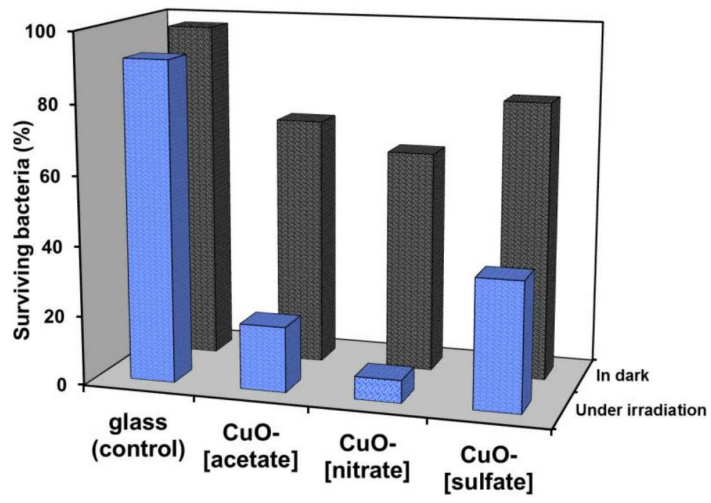

Fig. 5. Percentage of surviving bacteria in the presence of $\mathrm{CuO}$-[nitrate], $\mathrm{CuO}$-[acetate] and $\mathrm{CuO}$-[sulfate] micro/nanostructured powders in dark and under visible light irradiation for $3 \mathrm{~h}$.

\section{Conclusions}

$\mathrm{CuO}$ micro/nanostructures were hydrothermally synthesized by using $\mathrm{Cu}$-[nitrate], $\mathrm{Cu}$-[acetate] and $\mathrm{Cu}$ - [sulfate] precursors. It was found that all samples were crystallized in monoclinic crystal structure of $\mathrm{CuO}$ phase, independent of the precursors used. Due to the importance of effective surface area, sharp edges and intrinsic $\mathrm{OH}$-radicals of the nanostructures in (photo)inactivation of bacteria, the one-dimensional $\mathrm{CuO}$ nanorods grown in nitrate bath exhibited the highest photocatalytic antibacterial activity (with $\approx 94 \%$ photoinactivation of $E$. coli bacteria under $3 \mathrm{~h}$ visible light irradiation) among the micro/nanostructures synthesized in this work. This study can provide more information for upcoming antibacterial applications of copper oxide nanostructures as effective and inexpensive photocatalysts.

\section{Acknowledgments}

The authors would like to thank the Research Council of Sharif University of Technology and the Iran National Science Foundation for supporting the work.

\section{References}

[1] X. Wu, G. Shi, S. Wang, P. Wu, Eur. J. Inorg. Chem. 2005, 4775 (2005).

[2] J.B. Liang, N. Kishi, T. Soga, T. Jimbo, Appl. Surf. Sci. 257, 62 (2010).

[3] O. Akhavan, J. Phys. D Appl. Phys. 41, 235407 (2008).

[4] Y. Liu, Y. Chu, Y. Zhuo, M. Li, L. Li, L. Dong, Cryst. Growth Des. 7, 467 (2007).

[5] Y. Wang, D. Meng, X. Liu, F. Li, Cryst. Res. Technol. 44, 1277 (2009).

[6] J. Liu, X. Huang, Y. Li, K.M. Sulieman, X. He, F. Sun, J. Mater. Chem. 16, 4427 (2006).

[7] R.P. Wijesundera, Semicond. Sci. Technol. 25, 045015 (2010).

[8] T.J. Richardson, J.L. Slack, M.D. Rubin, Electrochim. Acta 46, 2281 (2001).

[9] O. Akhavan, H. Tohidi, A.Z. Moshfegh, Thin Solid Films 517, 6700 (2009).

[10] M. Zhou, Y. Gao, B. Wang, Z. Rozynek, J.O. Fossum, Eur. J. Inorg. Chem. 2010, 729 (2010).

[11] Z. Ai, L. Zhang, S. Lee, W. Ho, J. Phys. Chem. C 113, 20896 (2009).

[12] M. Vaseem, A. Umar, Y.B. Hahn, D.H. Kim, K.S. Lee, J.S. Jang, J.S. Lee, Catal. Commun. 10, 11 (2008).

[13] A. Chowdhuri, P. Sharma, V. Gupta, K. Sreenivas, K.V. Rao, J. Appl. Phys. 92, 2172 (2002).

[14] X. Zhang, G. Wang, X. Liu, J. Wu, M. Li, J. Gu, H. Liu, B. Fang, J. Phys. Chem. C 112, 16845 (2008).

[15] O. Akhavan, E. Ghaderi, J. Mater. Chem. 21, 12935 (2011).

[16] Y.W. Zhu, T. Yu, F.C. Cheong, X.J. Xu, C.T. Lim, V.B.C. Tan, J.T.L. Thong, C.H. Sow, Nanotechnology 16, 88 (2005).

[17] Y. Liu, L. Zhong, Z. Peng, Y. Song, W. Chen, J. Mater. Sci. 45, 3791 (2010). 
[18] O. Akhavan, E. Ghaderi, Surf. Coat. Technol. 205, 219 (2010).

[19] F. Gao, H. Pang, S. Xu, Q. Lu, Chem. Commun. 24, 3571 (2009).

[20] M. Paschoalino, N.C. Guedes, W. Jardim, E. Mielczarski, J.A. Mielczarski, P. Bowen, J. Kiwi, J. Photochem. Photobiol. A Chem. 199, 105 (2008).

[21] O. Akhavan, R. Azimirad, S. Safa, E. Hasani, J. Mater. Chem. 21, 9634 (2011).

[22] R. Azimirad, S. Safa, Synth. React. Inorg. Met.-Org. Chem. 44, 798 (2014).

[23] I. Perelshtein, G. Applerot, N. Perkas, E. Wehrschuetz-Sigl, A. Hasmann, G. Guebitz, A. Gedanken, Surf. Coat. Technol. 204, 54 (2009).

[24] O. Akhavan, E. Ghaderi, J. Phys. Chem. C 113 , 20214 (2009).

[25] G. Fu, P.S. Vary, C.T. Lin, J. Phys. Chem. B 109, 8889 (2005)

[26] O. Akhavan, M. Abdolahad, Y. Abdi, S. Mohajerzadeh, Carbon 47, 3280 (2009).

[27] O. Akhavan, J. Coll. Interface Sci. 336, 117 (2009).

[28] N. Jones, B. Ray, K.T. Ranjit, A.C. Manna, FEMS Microbiol. Lett. 279, 71 (2008).

[29] O. Akhavan, M. Mehrabian, K. Mirabbaszadeh, R. Azimirad, J. Phys. D Appl. Phys. 42, 225305 (2009).

[30] O. Akhavan, M. Choobtashani, E. Ghaderi, J. Phys. Chem. C 116, 9653 (2012).

[31] F.C.S. Paschoalino, M.P. Paschoalino, E. Jordăo, W.D. Jardim, Open J. Phys. Chem. 2, 135 (2012).
[32] L.J. Xie, W. Chu, J.H. Sun, P. Wu, D.G. Tong, J. Mater. Sci. 46, 2179 (2011).

[33] H. Pang, F. Gao, Q. Lu, Chem. Commun. 9, 1076 (2009).

[34] M.S. Hasan, T. Amna, H.Y. Kim, M.S. Khil, Composites Part B 45, 904 (2013).

[35] S. Wang, H. Xu, L. Qian, X. Jia, J. Wang, Y. Liu, W. Tang, J. Solid State Chem. 182, 1088 (2009).

[36] J. Cho, Solid State Ion. 138, 267 (2001).

[37] L. Vayssieres, Adv. Mater. 15, 464 (2003).

[38] S. Cho, S. Jung, K.H. Lee, J. Phys. Chem. C 112 , 12769 (2008).

[39] M.A. Abbasi, Y. Khan, S. Hussain, O. Nur, M. Willander, Vacuum 86, 1998 (2012).

[40] J.S. Xue, J.R. Dahn, J. Electrochem. Soc. 142, 3668 (1995).

[41] C. Chen, Y. Zheng, Y. Zhan, X. Lin, Q. Zheng, K. Wei, Cryst. Growth Des. 8, 3549 (2008).

[42] E. Kim, Z. Jiang, K. No, Jpn. J. Appl. Phys. 39, 4820 (2000).

[43] O. Akhavan, E. Ghaderi, ACS Nano 4, 5731 (2010).

[44] S. Kang, M. Herzberg, D.F. Rodrigues, M. Elimelech, Langmuir 24, 6409 (2008).

[45] J.P. Ruparelia, A.K. Chatterjee, S.P. Duttagupta, S. Mukherji, Acta Biomater. 4, 707 (2008). 